\title{
LA DINÁMICA "NEODUALISTA" DE UNA DEMOCRACIA SIN SISTEMA DE PARTIDOS: LA SITUACIÓN DE LA DEMOCRACIA EN EL Perú
}

\author{
Neodualism in a Democracy Without Party System. \\ Democracy in Peru
}

\author{
MARTÍN TANAKA \\ Pontificia Universidad Católica del Perú \\ SOFÍA VERA ROJAS \\ Pontificia Universidad Católica del Perú
}

\begin{abstract}
RESUMEN
La democracia peruana actual sufre de una muy baja legitimidad de sus instituciones, debilidad de su sistema de partidos y la continua irrupción de outsiders. El desempeño de la economía muestra mejores indicadores a los promedios latinoamericanos y, al mismo tiempo, el país enfrenta altos niveles de descontento ciudadano que se expresan en la preferencia por opciones políticas con componentes antisistema y crecientes niveles de conflicto social. Este artículo plantea que el legado de las reformas estructurales del fujimorismo ha generado una situación "neodualista", donde convive un sector moderno y en crecimiento, que opta por opciones políticas moderadas, con uno relativamente estancado y excluido que simpatiza con retóricas antisistema.
\end{abstract}

Palabras clave: Perú, democracia, partidos políticos, desigualdad socioeconómica.

\begin{abstract}
Peruvian democracy faces low levels of institutional legitimacy, a weak party system and the recurrent appearance of outsiders in the political arena. The performance of the economy presents better indicators than the Latin American average, and, at the same time, the country suffers from high levels of social discomfort, expressed through the preference for anti-system candidates, and increasing levels of social conflict. This article argues that the legacy of the structural reforms implemented by Fujimori has generated a "neo-dualist" situation, where a modern and growing sector that supports moderate policies coexists with a marginalized sector that sympathizes with anti-system rhetoric.
\end{abstract}

Key words: Peru, democracy, political parties, socioeconomic inequality. 


\section{INTRODUCCIÓN}

Cuando se analiza el estado de la democracia en Latinoamérica se suelen mencionar entre sus principales problemas la baja legitimidad de las instituciones y la debilidad de sus sistemas de partidos, consecuencia del descontento que causan los bajos niveles de ejercicio efectivo de derechos económicos y sociales. ${ }^{1}$ Los altos niveles de inestabilidad y volatilidad electoral y de movilización y polarización social, así como la irrupción de outsiders y de propuestas que plantean la refundación del orden político a través de asambleas constituyentes y otras medidas similares, son síntomas de este fenómeno.

Cuadro 1: Confianza en instituciones (Latinobarómetro, 2008)

\begin{tabular}{lcc}
\hline País & Congreso & Partidos \\
\hline Uruguay & 50 & 36 \\
El Salvador & 48 & 39 \\
Paraguay & 41 & 23 \\
Venezuela & 41 & 32 \\
República Dominicana & 38 & 27 \\
Ecuador & 36 & 15 \\
Brasil & 34 & 20 \\
Chile & 32 & 16 \\
Argentina & 31 & 14 \\
México & 31 & 17 \\
Colombia & 28 & 20 \\
Costa Rica & 27 & 20 \\
Honduras & 26 & 20 \\
Bolivia & 25 & 12 \\
Nicaragua & 23 & 24 \\
Guatemala & 22 & 23 \\
Panamá & 18 & 16 \\
Perú & 12 & 11 \\
Latinoamérica & 32 & 21 \\
\hline Fuente: Latinoánetrong & & \\
\hline & & \\
\hline
\end{tabular}

Fuente: Latinobarómetro 2008.

Perú posee el nivel más bajo de confianza en las instituciones de América Latina según datos del Latinobarómetro 2008 (Cuadro 1). Según datos de Ipsos-Apoyo de 2008, ${ }^{2}$ tres instituciones fundamentales para la democracia (el Poder Judicial, el Congreso y los partidos) son las instituciones que menos confianza inspiran en los ciudadanos. Al 
mismo tiempo, Perú exhibe la más alta volatilidad electoral en la región, ocupando el último puesto en el índice de volatilidad (Jones, 2005). También es muy bajo el nivel del enraizamiento social de los partidos políticos peruanos (Jones, 2005), que en referencia a los 18 países de la región se encuentra muy por debajo del promedio. Asimismo, el índice de legitimidad de los partidos ubica a Perú en el puesto 12 de la región. Tomando en cuenta estos indicadores, además de la organización de los partidos, Jones (2005) estima un índice de institucionalización para los 18 países en cuestión, donde Perú se sitúa entre los tres últimos puestos (Cuadro 2).

Cuadro 2. Índice de institucionalización del sistema de partidos y sus componentes

\begin{tabular}{lccccc}
\hline & $\begin{array}{c}\text { Índice de } \\
\text { institucionalización }\end{array}$ & $\begin{array}{c}\text { Volatilidad } \\
\text { electoral }\end{array}$ & $\begin{array}{c}\text { Enraizamiento } \\
\text { de partidos }\end{array}$ & $\begin{array}{c}\text { Legitimidad } \\
\text { de partidos }\end{array}$ & $\begin{array}{c}\text { Organización } \\
\text { de partidos }\end{array}$ \\
\hline Uruguay & 76 & 84 & 73 & 51 & 97 \\
Rep. Dominicana & 74 & 75 & 75 & 50 & 98 \\
Nicaragua & 70 & 84 & 62 & 34 & 98 \\
Honduras & 68 & 94 & 66 & 40 & 74 \\
México & 67 & 88 & 62 & 33 & 85 \\
Panamá & 67 & 77 & 66 & 41 & 83 \\
El Salvador & 66 & 90 & 62 & 35 & 78 \\
Chile & 65 & 95 & 49 & 40 & 77 \\
Paraguay & 64 & 79 & 82 & 32 & 65 \\
Argentina & 62 & 74 & 46 & 34 & 94 \\
Costa Rica & 61 & 77 & 62 & 40 & 67 \\
Colombia & 60 & 89 & 49 & 30 & 73 \\
Brasil & 59 & 80 & 49 & 40 & 66 \\
Bolivia & 56 & 66 & 60 & 26 & 72 \\
Venezuela & 55 & 60 & 47 & 42 & 73 \\
Perú & 53 & 51 & 54 & 34 & 75 \\
Ecuador & 53 & 73 & 53 & 23 & 62 \\
Guatemala & 48 & 58 & 45 & 34 & 58 \\
\hline
\end{tabular}

Fuente: Jones, 2005.

Las elecciones de 2006 ilustran el funcionamiento actual del sistema de partidos. El ganador de la primera vuelta de la elección presidencial, Ollanta Humala, fue un candidato improvisado y lejano al mundo de la política institucional, cuya alianza política fue formada con poca anticipación a las elecciones y se desplomó después de que su líder fue derrotado en la segunda vuelta. Tal era su fragilidad que en las elecciones regionales celebradas cinco meses después de las presidenciales, el Partido Nacionalista de Humala obtuvo apenas el 8\% de los votos para la elección de presidentes de región. No ganó ninguna de las 25 regiones y obtuvo apenas el 6\% de los votos para la elección de alcaldes provinciales, apenas el 5\% de las 195 alcaldías en disputa (Cuadro 3). Las 
consecuencias de tener partidos poco institucionalizados se observan también a través de su comportamiento en el Congreso, donde la incoherencia y la indisciplina son muy frecuentes. Apenas inaugurado el periodo legislativo del Congreso de la República del 2006, la bancada de la alianza electoral de Ollanta Humala se fragmentó de manera progresiva, provocando el debilitamiento del bloque de la oposición parlamentaria. De los 45 congresistas electos, en febrero de 2009 el humalismo controlaba apenas 23. La debilidad de los partidos ayuda a entender los problemas de gestión que tienen las autoridades, la desconfianza que sienten los ciudadanos frente a éstas y la creciente conflictividad.

Cuadro 3: Porcentaje de votos válidos en elecciones nacionales, regionales y provinciales 2006

\begin{tabular}{lrrr}
\hline Organizaciones políticas & Nacional & Regional & Provincial \\
\hline Partido Nacionalista $^{1}$ & 30,6 & 8,0 & 6,0 \\
Partido Aprista Peruano & 24,3 & 18,5 & 13,8 \\
Unidad Nacional & 23,8 & 3,3 & 17,2 \\
Alianza por el Futuro & 7,4 & - & - \\
Acción Popular ${ }^{2}$ & 5,8 & 2,0 & 3,6 \\
Coordinadora Nacional de Independientes & - & 0,5 & 0,5 \\
Somos Perú & - & 0,5 & 5,0 \\
Unión por el Perú & - & 5,5 & 5,3 \\
Restauración Nacional & 4,4 & 3,1 & 7,3 \\
Concertación Descentralista & 0,6 & - & - \\
Partido Justicia Nacional & 0,5 & - & 0,1 \\
Partido Socialista & 0,5 & 0,0 & 0,2 \\
Alianza para el Progreso & 0,4 & 1,3 & 3,7 \\
Con fuerza Perú & 0,3 & 0,2 & 0,2 \\
Sí Cumple & - & 2,3 & 2,6 \\
Perú Posible & - & 1,5 & 0,3 \\
Otros & 1,34 & 53,3 & 34,2 \\
Total & 100,0 & 100,0 & 100,0 \\
\hline
\end{tabular}

1 El Partido Nacionalista postuló en las elecciones presidenciales junto con Unión por el Perú.

2 Acción Popular, Somos Perú y Coordinadora Nacional de Independientes conforman el Frente de Centro que postula a las elecciones presidenciales.

Fuente: Tanaka y Vera, 2007.

Lo paradójico del caso peruano es que estos elementos conviven con una dinámica de crecimiento económico sostenido. Según datos del INEI, Perú tiene la segunda tasa de crecimiento promedio anual del periodo 2002-2007 más alta de América Latina y el Caribe. El Presupuesto General de la República más que se duplicó entre 2000 y el recientemente aprobado presupuesto de apertura de 2010. La existencia de más 
recursos ha hecho evidente la precariedad institucional del Estado, que se expresa en las dificultades para gastar con rapidez y eficiencia los fondos existentes. La existencia de recursos que no se gastan genera críticas que impulsan a las autoridades a gastar de manera rápida e ineficiente, lo que a su vez genera la percepción de malos manejos y corrupción, ahondando los problemas de legitimidad de las autoridades en un círculo vicioso. Esto ayuda a entender los bajos niveles de aprobación a la gestión de los últimos dos presidentes (Alan García y Alejandro Toledo), a diferencia de lo que ocurre en otros países andinos donde los presidentes cuentan con un respaldo ciudadano mayoritario (Chávez, Uribe, Correa, Morales). Una consecuencia de esta situación son las protestas sociales que se desarrollan en todo el país con reclamos muy particulares y variados (Gráficos 1 y 2). Sin embargo, las protestas sociales están muy desarticuladas y debilitadas. Las múltiples manifestaciones de descontento social, ya sea a través de la confrontación o del diálogo, también padecen fragmentación y localismo. Las reivindicaciones son muy diferentes, los contextos sociales y los actores envueltos en la acción colectiva varían entre sí y pocas veces comparten elementos comunes. ${ }^{3}$

\section{Gráfico 1: Perú 1995-2006: Protestas por año}

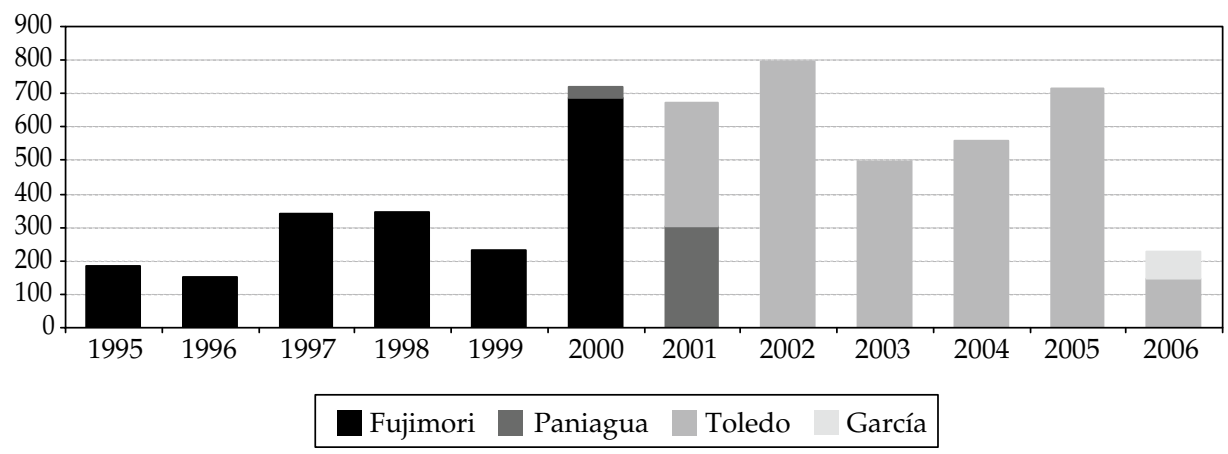

Fuente: Tanaka y Garay, 2009.

Si bien desde la caída del fujimorismo la democracia ha avanzado mucho en términos institucionales, hace falta fortalecer la capacidad de los actores políticos y sociales, en especial aquellos vinculados a los sectores más marginalizados para hacer llegar sus demandas al sistema político. A pesar de que se ha implementado un amplio conjunto de mecanismos de participación ciudadana en distintos niveles del Estado, ${ }^{4}$ éstos son utilizados por organizaciones que enfrentan problemas de representatividad. Como consecuencia, la arena política deja mucho espacio para la aparición de opciones con fuertes componentes antipolíticos y antisistema. Por lo tanto, la clave para enfrentar los desafíos de la democracia en el Perú pasa por una reforma del Estado y por estrategias de fortalecimiento de los actores sociales y políticos. 
Gráfico 2: Conflictos registrados por la Defensoría del Pueblo, enero 2006-septiembre 2009

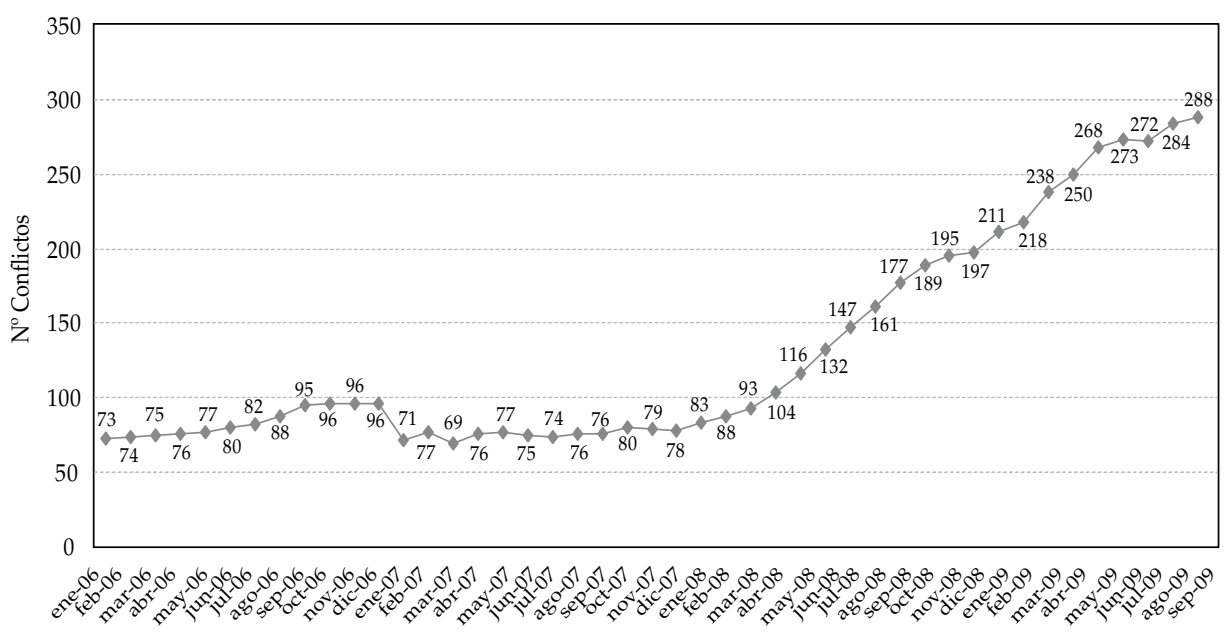

Fuente: Defensoría del Pueblo.

A continuación esbozaremos una explicación de cómo y por qué se ha llegado a la situación descrita, y luego presentaremos una descripción sobre la situación de las distintas dimensiones involucradas en el funcionamiento de la democracia en el Perú.

\section{EL LEGADO DEL FUJIMORISMO, LA “TRANSICIÓN" Y LA REINSTITUCIONALIZACIÓN DEMOCRÁTICA}

Lo que define la situación de la democracia en el Perú actual es el legado del fujimorismo, marcado por la debilidad del Estado y de los actores políticos y sociales, por las orientaciones de política económica establecidas bajo el Consenso de Washington y por la importancia de un discurso que impregnó la cultura política de elementos antipolíticos y antiinstitucionales. Este legado ha dificultado tanto las iniciativas que buscaban generar un proceso de reinstitucionalización democrática, como el aprovechamiento de la situación económica favorable para reducir la pobreza y la exclusión social.

En 1980 se celebraron elecciones democráticas después de doce años de dictadura militar y se inició el proceso de construcción de un sistema de partidos que parecía ser representativo. El sistema que hasta el momento había alcanzado cierta estabilidad estaba conformado por Izquierda Unida, el Partido Aprista Peruano, Acción Popular y el Partido Popular Cristiano. Se trataba de cuatro fuerzas políticas con bases sociales sólidas, articuladas a sindicatos, gremios y organizaciones de distinto tipo, en una lógica de competencia que seguía antagonismos ideológicos y que congregaba a la gran mayoría de las preferencias electorales. Este sistema enfrentaba tensiones y desafíos: una gran movilización social, una crisis económica que llegó a niveles hiperinflacionarios 
a finales de la década y el desafío de la insurgencia de dos grupos terroristas, Sendero Luminoso y el Movimiento Revolucionario Túpac Amaru (MRTA).

Este sistema de partidos sufrió un revés importante cuando en 1990 Alberto Fujimori alcanzó la presidencia, al ganar en la segunda vuelta electoral. Fujimori no contaba con ninguna experiencia política previa y ganó sobre la base de un discurso contrario a los partidos tradicionales. Fujimori no contaba con mayoría en el Congreso y tenía una bancada inexperta e indisciplinada; sin embargo, consolidó su poder al controlar la crisis económica mediante la aplicación de un duro programa de ajuste estructural que tuvo muy altos costos sociales. A pesar de que durante la campaña electoral Fujimori criticó la propuesta de reforma neoliberal de su adversario, el escritor Mario Vargas Llosa, una vez en el poder justificó la necesidad de implementarla como la única salida posible a la crisis.

El control de la crisis económica le permitió a Fujimori legitimar sus posiciones críticas frente al papel del Congreso y los partidos de oposición. Con el pretexto de que el Congreso limitaba sus posibilidades de ejercer el poder, organizó un golpe de Estado en abril de 1992 mediante el cual declaró en reorganización a todos los poderes del Estado. Convocó a elecciones a finales de 1992 para conformar el Congreso Constituyente Democrático, que redactó una nueva Constitución aprobada por el referéndum de 1993 y a elecciones generales en 1995. En ambas ocasiones el fujimorismo logró cómodas mayorías, lo que le permitió construir un poder personalista sin restricciones. La desaparición de una dinámica pluralista y equilibrada dio lugar a un régimen autoritario legitimado plebiscitariamente. $^{5}$

La manera en la que se implementaron las reformas neoliberales en los años noventa estableció ciertos principios y estilos presentes en la forma en que funciona el Estado y se desarrollan las políticas públicas. El contexto autoritario y centralista de las reformas hizo que descansaran en pequeñas islas de eficiencia que convivieron con un aparato estatal debilitado, con escasas capacidades para implementar políticas complejas, y vulnerable a la corrupción y a intereses particularistas. Esta orientación ortodoxa en la economía ha dado estabilidad al país y ha permitido altas tasas de crecimiento, pero al mismo tiempo ha dificultado avanzar en el logro de metas de desarrollo social.

En el terreno político y social, el fujimorismo hizo esfuerzos deliberados y exitosos para debilitar a las organizaciones políticas de oposición mediante discursos antipolíticos y antipartido. Como consecuencia, ha surgido una actitud "antisistema" en el país, visible en la proliferación de organizaciones improvisadas, personalistas y pragmáticas. El fujimorismo también debilitó organizaciones sociales e instituciones de la sociedad civil, desarrollando una relación clientelar entre el Estado y la sociedad. El tejido social -ya socavado por la crisis económica de los años ochenta, el cambio de modelo económico, las medidas de ajuste estructural y el conflicto armado interno- se debilitó aún más por el funcionamiento de la maquinaria clientelista del fujimorismo. En la actualidad no hay

5 Ver Tanaka, 1998 y 2006. Sobre las décadas de los años ochenta y noventa ver también Cameron y Mauceri eds., 1997; Carrión, ed., 2006; y Crabtree, ed., 2006, entre muchos otros. 
actores con voluntad de cambiar las cosas y aquellos que quisieran hacerlo no tienen las capacidades políticas, los cuadros suficientes, o instituciones eficaces que puedan implementar tales proyectos.

Durante los gobiernos de Paniagua y Toledo hubo esfuerzos por restituir el pluralismo político y el equilibrio entre los poderes del Estado. Se trató de conducir la política económica en una dirección más inclusiva, reformar e institucionalizar el Estado, fortalecer el sistema de partidos y abrir espacios de participación a la sociedad civil. Se emprendieron reformas para restablecer la autonomía del Congreso, los organismos electorales y el Poder Judicial. No sólo se dieron reformas en un sentido horizontal (entre los diversos poderes y agencias del Estado nacional), sino también vertical (en cuanto a las relaciones entre los niveles nacional, regional y local). Se buscó hacer cambios en la conducción de la economía que integraran más al país y redujeran los niveles de pobreza, se emprendió una serie de reformas al sistema electoral y de partidos y se impulsaron reformas para incentivar la participación ciudadana. Sin embargo, los resultados han sido parciales; la situación peruana actual se inscribe en la tensión entre la herencia descrita y los avances en profundización democrática, que marcan una situación que podríamos llamar "neodualista", para distinguirla del dualismo clásico de la sociología latinoamericana.

Los avances más importantes se dieron en el plano institucional, a pesar de que fracasó un intento de reforma integral de la Constitución de 1993. Se consiguió progresar en el fortalecimiento de la autonomía del Congreso (se restableció la elección en circunscripciones departamentales), el Poder Judicial y otros organismos y agencias del Estado, entre ellas las agencias de control y fiscalización, así como en la institucionalización de las fuerzas armadas y policiales. La reforma estatal más importante ha sido la regionalización y descentralización del Estado, que tuvo como cambio emblemático la elección popular de presidentes regionales en los 25 departamentos del país. Dentro de este proceso de cambios se implementó una legislación que abrió las puertas del sistema político a mecanismos de participación y consulta ciudadana en todos los niveles de gobierno (donde destacan los presupuestos participativos y los Consejos de Coordinación Regional y Local). Al mismo tiempo, se aprobó una ley de partidos que buscó elevar las barreras de entrada al sistema para fortalecer a los partidos más consolidados.

En términos de una reforma institucional del Estado orientada en un sentido social o redistributivo, parece haberse abandonado la intención de emprender una reforma profunda, más allá de algunos avances sectoriales. En la actualidad el debate se ha reducido a la modernización de la administración pública en términos de eficiencia y transparencia; aun en estos términos los avances son escasos. En cuanto a las reformas que buscan mejorar la representación política, los avances también son insuficientes. $\mathrm{Ni}$ la ley de partidos, ni la ley de barrera electoral, ni el cambio en las circunscripciones electorales del Congreso o en su reglamento han logrado evitar mayores niveles de fragmentación política. El Congreso sigue siendo una institución que despierta muy poca confianza en la ciudadanía y no se han podido establecer consensos para emprender reformas de fondo, como la eliminación del voto preferencial o la instauración de la bicameralidad. 
La introducción de espacios regionales y locales de competencia política creó la esperanza de una verdadera renovación. Sin embargo, los movimientos regionales adolecen de problemas similares a los de los partidos nacionales. La presencia de organizaciones sociales en los nuevos espacios de participación no garantiza que la mayoría de la población sea escuchada y atendida. Las organizaciones sociales son poco representativas y tienden a funcionar más como grupos de interés particularista. Por último, la representación social tiende a ser controlada por brokers regionales y locales.

Como conclusión, al evaluar el funcionamiento de la democracia en el Perú, encontramos en los últimos años un panorama de avances parciales en cuanto a institucionalización y ejercicio de derechos civiles, políticos y sociales, pero que arrastran el peso de un modelo económico y de una herencia autoritaria que generan una dinámica escindida que da lugar a mucha incertidumbre de cara a las próximas elecciones de los años 2010 y 2011. En tanto entendemos la democracia como un régimen político, pero basado en un Estado y en unas instituciones que garantizan los derechos ciudadanos fundamentales, veremos a continuación la situación actual de estas dimensiones.

\section{DEMOCRACIA ELECTORAL}

\section{a. Derecho al voto}

En el Perú el derecho al voto es conferido a todos los adultos sin ninguna restricción formal. El sufragio universal se alcanzó en la Constitución de 1979, que incluyó por primera vez a analfabetos y redujo la mayoría de edad de 21 a 18 años. El efecto práctico de esta medida fue la inclusión electoral de la población indígena, que era marginada de las urnas en tanto el analfabetismo se concentra en poblaciones con lenguas nativas. El reconocimiento del derecho al voto de diversos grupos sociales ha seguido un proceso paulatino con una tendencia clara a la ampliación democrática. El voto de las mujeres, por ejemplo, fue reconocido formalmente en 1933 pero no fue practicado hasta 1963. Asimismo, en 2005 se suprimió una última restricción cuando se aprobó el voto de las fuerzas militares y policiales en actividad.

Por otro lado, además de ser un derecho, en Perú el voto es una obligación. La omisión al ejercicio del sufragio es considerada una falta que es sancionada con una multa. Para votar no es necesario inscribirse en un padrón electoral, cualquier persona que posea un Documento Nacional de Identidad (DNI) puede ejercer este derecho. Este marco jurídico favorece la participación electoral, por lo que los niveles de ausentismo han disminuido en los últimos años, pasando de 26\% en 1995 al 12\% en el 2006. Además, en comparación con los demás países de la región, los niveles de participación electoral declarada (LAPOP, 2006) son los más altos, alcanzando en las últimas elecciones del 2006 un $92 \%$ de participación electoral.

Sin embargo, existen en la práctica algunas restricciones informales al ejercicio del voto: se estima que más de millón y medio de peruanos no cuenta con el DNI, la mayoría habitantes de zonas rurales, mujeres e indígenas, según cálculos del Registro Nacional 
de Identificación y Estado Civil (RENIEC). El RENIEC ha iniciado una serie de campañas de acceso gratuito al DNI en comunidades rurales con el objetivo de reducir el número de indocumentados en el país. También se ha eliminado la Libreta Militar (registro ante algunas de las tres fuerzas armadas) como requisito previo a la obtención del DNI pues encarecía el trámite de la documentación. A pesar de que no existen resultados oficiales de estas campañas se espera que favorezcan de manera progresiva la participación electoral. En 2006 se observó una disminución del ausentismo electoral, registrándose valores muy por debajo del promedio histórico, lo cual podría deberse a que se ha aliviado el problema de la indocumentación y a que se ha avanzado en la actualización del sistema de registro civil.

\section{b. Elecciones limpias}

Durante el gobierno de Fujimori las elecciones fueron bastante irregulares: hubo denuncias de fraude en el referéndum de 1993 y en los comicios de 2000. En esos años se denunció la utilización de recursos del Estado para la campaña del Presidente, la manipulación de los organismos electorales y el control de los medios de comunicación. Después de la caída del fujimorismo, las elecciones han logrado estándares internacionales de transparencia, y la legitimidad del proceso electoral no ha vuelto a ser cuestionada ni por la ciudadanía, los actores políticos o por organismos internacionales.

El caso más emblemático de irregularidades electorales de los últimos veinte años se dio en el proceso electoral del 2000. El fujimorismo había logrado introducir a través del Congreso la Ley de Interpretación Auténtica que avalaba una segunda reelección al afirmar que, dada la nueva Constitución de 1993, la reelección de Fujimori de 1995 debía considerarse su primer mandato y, por ende, la primera reelección se daría en el año 2000. El Congreso destituyó a tres magistrados que desde el Tribunal Constitucional consideraron dicha ley inconstitucional.

En este escenario de discutida legitimidad de la candidatura de Alberto Fujimori, organismos internacionales y nacionales de observación electoral denunciaron irregularidades en la campaña electoral. Se denunció que el fujimorismo había utilizado recursos públicos para financiar su campaña y que se habría valido de recursos de programas de alimentación del Estado para atraer electores; sumado a esto, aparecieron campañas de difamación en contra de los principales opositores a través de medios de comunicación manipulados, además del amedrentamiento de los medios a través de las fuerzas del orden y el Servicio de Inteligencia. Otras instituciones, como el Poder Judicial y los organismos electorales, también sufrieron manipulaciones políticas. ${ }^{6}$

Uno de los cambios más importantes tras la caída del fujimorismo es la restitución de la independencia de los organismos electorales. Las elecciones de 2001 y 2006 se dieron en un contexto de tranquilidad, sin los sobresaltos que caracterizaron a las elecciones del 2000. Pasadas aquellas irregularidades, los organismos electorales mejoraron 
sustancialmente sus niveles de credibilidad y legitimidad. En una encuesta de diciembre del 2007, aplicada por la Universidad de Lima, el RENIEC se ubica en el primer lugar de la confianza ciudadana entre todas las instituciones públicas, mientras que el JNE y la ONPE en los puestos 10 y 13 de un total de 31 entidades evaluadas. El aumento de la confianza en este tipo de instituciones es evidente si observamos que en la encuesta del 2007 la ONPE y el JNE alcanzaron 58\% y 55\% de confianza, mientras que dos años antes sólo llegaban al 38\% y 33\% respectivamente (Gráfico 3).

Gráfico 3: Aumento de la confianza en RENIEC, ONPE y JNE (2005- 2007)

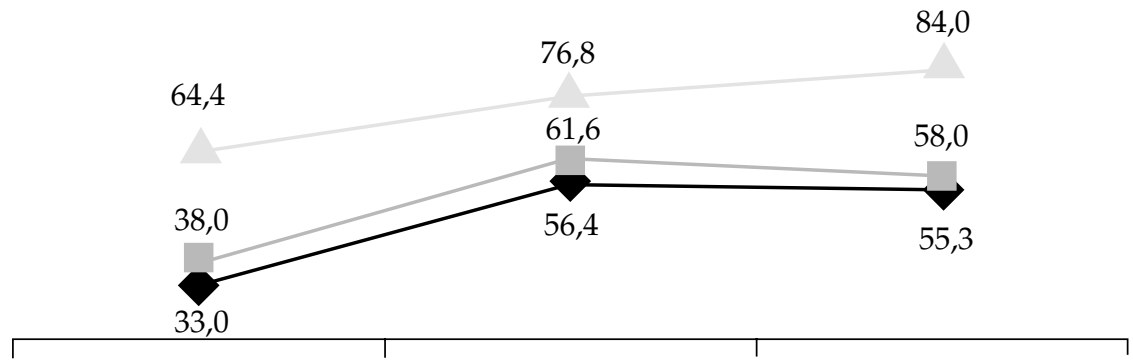

$\begin{array}{lll}\text { Nov. } 2005 \text { Dic. } 2006 & \text { Oct. } 2007\end{array}$

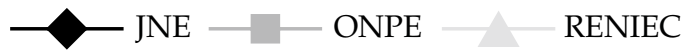

Fuente: Universidad de Lima, 2007.

Los problemas pendientes se refieren a temas que afectan la transparencia financiera y las condiciones de equidad en la competencia electoral. Se tiene que mejorar algunos aspectos de la organización del proceso electoral y hacer que los partidos políticos cumplan cabalmente con las disposiciones de la Ley de Partidos Políticos. Asimismo, se debe trabajar en el tema del financiamiento a los partidos para evitar desigualdades que afecten la equidad de la competencia. La legislación peruana contempla un tope para la recepción de aportes privados, sin embargo no existe un reglamento que lo respalde con sanciones para los partidos que incumplan la ley o topes específicos para los gastos en materia de campañas electorales. ${ }^{7}$ Los partidos políticos tienen la obligación de presentar informes financieros anuales ${ }^{8}$ pero en el 2006 sólo nueve de los 37 partidos registrados cumplieron a tiempo con esa obligación.

$7 \quad$ Según el artículo $34^{\circ}$ de la Ley de Partidos Políticos y el artículo $67^{\circ}$ del Reglamento de Financiamiento y Supervisión de Fondos Partidarios, y artículo $183^{\circ}$ de la Ley Orgánica de Elecciones.

$8 \quad$ Ley Orgánica de Elecciones Nº 26859 , artículo 183. 


\section{c. Elecciones libres}

Perú no presenta restricciones significativas en cuanto a la libertad para escoger entre alternativas electorales y para competir en un proceso electoral. La tendencia actual avanza hacia el fortalecimiento de las garantías legales para propiciar la libre competencia e incentivar la participación de nuevos actores políticos. La gama de partidos inscritos en el registro de organizaciones políticas para competir en procesos electorales ha aumentado en los últimos años. En las elecciones del 2006, 20 organizaciones políticas presentaron candidaturas para Presidente, frente a 9 y 8 en los años anteriores, asimismo 24 organizaciones políticas presentaron candidaturas para el Congreso, mientras que sólo 10 en 2001 y 13 en 2000.

Si bien el aumento de partidos políticos en las elecciones del 2006 garantizó a los electores una amplia oferta política, consideramos que la dispersión incidió en los problemas de representación. Es probable que un alto número de participantes afecte el promedio de la calidad de la oferta política debido al ingreso de organizaciones sin experiencia en la competencia electoral.

En términos prácticos tampoco existe ninguna restricción significativa a la inscripción de candidaturas, a la formación de partidos políticos o a la realización de campañas electorales. A diferencia del fujimorismo, que organizó campañas mediáticas de desprestigio en contra de los candidatos de oposición, los procesos electorales se desarrollan hoy en día en contextos libres y seguros.

\section{Autoridades elegidas asumen cargos}

La ley asegura el derecho a la designación de autoridades mediante elecciones y su permanencia en el cargo. Sin embargo, persisten problemas de fortaleza institucional de los actores políticos y de la burocracia, de quienes depende muchas veces que se cumplan los resultados electorales y los mandatos democráticos.

En el nivel nacional, las elecciones se han realizado desde 1980 cada cinco años sin ninguna restricción, aunque es importante señalar los problemas registrados durante los años del fujimorismo. La democracia peruana iniciada con la transición de 1978 se quebró con el golpe de Estado de 1992; meses más tarde hubo elecciones para nombrar a un Congreso Constituyente Democrático que redactó una nueva Constitución. Esta fue aprobada en un referéndum en 1993, en medio de serias denuncias de fraude. Mientras que las elecciones de 1995 se dieron sin exclusiones y sin cuestionamientos de fondo en cuanto a sus resultados, los comicios de 2000 presentaron serias irregularidades, aunque no fueron invalidados.

En el nivel subnacional regional se han elegido autoridades a través de elecciones universales en los años 2002 y 2006; de esta manera se retomó un proceso de descentralización y regionalización iniciado en 1988, que fue interrumpido por el "autogolpe" de Alberto Fujimori en 1992, quien buscó la centralización del poder en el Ejecutivo, eliminó los gobiernos regionales que estaban en formación y creó los Consejos Transitorios de Administración Regional (CTAR) para gobernar los departamentos bajo supervisión del gobierno. 
En el nivel local, las elecciones para alcaldes provinciales y distritales han continuado su calendario electoral sin ninguna alteración formal desde 1980, con excepción de las elecciones de 1992 que tuvieron que posponerse al año siguiente por la coyuntura del "autogolpe".

La permanencia de las autoridades electas en sus cargos suele ser respetada. Desde 1980 no ha habido ningún intento serio de remover de su cargo por vías extralegales a alguna autoridad nacional antes de la culminación de su mandato, salvo el "autogolpe" de Fujimori de 1992 y su renuncia a los pocos meses de haber sido reelecto presidente en las cuestionadas elecciones de 2000 a las que ya hicimos referencia. En general, salvo que haya procesos de revocatoria, que la ley contempla las autoridades electas se mantienen en sus puestos de gobierno hasta culminar su mandato. La revocatoria es una modalidad establecida en la Constitución de 1993, utilizada por ciudadanos descontentos con el desempeño de la autoridad y fuerzas de la oposición que aspiran a reemplazarla. En los últimos años el número de procesos de revocatoria ha aumentado, sobre todo en las pequeñas localidades rurales donde es más sencillo recolectar el número de firmas requeridas y donde también suele haber mayor fragmentación y conflictividad política. En 2008 se compraron 1,324 kits de revocatoria al JNE, para recolectar firmas en el 45\% de los gobiernos regionales y locales, mientras que en el 2004 sólo se vendieron 729 paquetes para recolectar firmas en 30\% de los mismos (Remy, 2008). Si bien el porcentaje de éxito de estas iniciativas es muy bajo, la revocatoria sigue siendo un indicador de los bajos niveles de legitimidad de las autoridades regionales y locales.

\section{DEMOCRACIA CONSTITUCIONAL}

\section{a. Independencia de los Poderes Legislativo y Ejecutivo}

En cuanto al funcionamiento independiente de los Poderes Legislativo y Ejecutivo, el mayor problema es la baja institucionalización de ambos poderes del Estado. La debilidad de los actores políticos que ocupan esos ámbitos compromete su capacidad para cumplir con sus funciones, lo que los hace vulnerables a las presiones de intereses particulares.

Desde el periodo de institucionalización democrática iniciado en noviembre de 2000, con la presidencia de Valentín Paniagua (hasta ese momento presidente del Congreso), no se han presentado amenazas serias de intrusión del Ejecutivo sobre el Legislativo. Más bien, el principal problema en la relación entre estos dos poderes es la fragmentación y volatilidad del sistema de partidos, lo que aumenta la incertidumbre y dificulta el establecimiento de acuerdos en el proceso legislativo. Como se observa en el Cuadro 4, ni Perú Posible ni el Partido Aprista han alcanzado controlar el 50\% de los curules del Congreso, por lo que han necesitado construir coaliciones con otros partidos, cuestión difícil de lograr por los problemas de indisciplina y ausencia de perfiles programáticos claros en los mismos. Perú Posible (2001-2006), un partido personalista e inexperto, estableció una alianza formal con el Frente Independiente Moralizador (FIM); mientras que el Partido Aprista (2006-2011), un partido antiguo y más consolidado, ha tenido que 
valerse de acuerdos coyunturales con grupos como Unidad Nacional, el fujimorismo, un sector de la Unión por el Perú y otros grupos menores. Al mismo tiempo, tampoco puede decirse que el Poder Ejecutivo enfrente un Congreso obstruccionista. En tanto la oposición es poco ideológica y está muy fragmentada, el Ejecutivo consigue la mayoría de sus proyectos mediante un proceso de negociación particularista. El panorama 20012006 y el 2006-2011 es muy diferente al visto entre 1993 y 2000, cuando el fujimorismo contaba con una mayoría parlamentaria abrumadora y muy disciplinada.

Cuadro 4: Porcentaje de escaños del partido de gobierno en el Legislativo (1990-2006)

\begin{tabular}{lcc}
\hline Partido de gobierno & Periodo Legislativo & \% de escaños \\
\hline Cambio 90 (diputados) & $1992-1995$ & 18 \\
Cambio 90 (senadores) & $1992-1995$ & 23 \\
Cambio 90-NM (CCD) & $1993-1995$ & 55 \\
Cambio 90-NM & $1995-2000$ & 56 \\
Perú 2000 & $2000-2001$ & 43 \\
Perú Posible & $2001-2006$ & 38 \\
Partido Aprista & $2006-2011$ & 30 \\
\hline
\end{tabular}

Fuente: Elaboración propia con datos de la ONPE.

Una de las maneras de comparar los niveles de independencia del Legislativo es a partir de la cantidad de decretos de urgencia dictados por cada gobierno. ${ }^{9}$ En Perú los poderes "proactivos" del Ejecutivo en materia legislativa son considerados amplios, comparados con otros países latinoamericanos (Payne, 2003). Sin embargo, determinados partidos políticos han tenido mayor éxito en emitir decretos de urgencia desde el gobierno. En el Cuadro 5 se observa que los decretos de urgencia dictados durante el fujimorismo alcanzaron el 72\% y $62 \%$ de la totalidad de leyes emitidas entre 1992-1995 y 1993-1995. Entre 1995 y 2000, el porcentaje baja a 38\%, pero cabe recordar que el gobierno contaba con una mayoría muy disciplinada en el Congreso, lo que hacía el recurso de los decretos poco necesario, además que no se vivió la situación de excepcionalidad característica de la primera mitad de la década de los años noventa. En cambio, en el gobierno de Toledo los decretos de urgencia no superaron el 13\% y en lo que va del gobierno aprista sólo se ha alcanzado el $18 \%$.

La incertidumbre en los procesos legislativos es alta con un Congreso fragmentado, partidos políticos poco cohesionados y legisladores pragmáticos y personalistas. Esto hace al proceso legislativo arbitrario, impredecible y sensible a intereses individuales, donde las iniciativas de leyes pocas veces siguen una agenda legislativa preestablecida y

Según el artículo 118 de la Constitución de 1993 corresponde al Presidente de la República “Dictar medidas extraordinarias, mediante decretos de urgencia con fuerza de ley, en materia económica y financiera, cuando así lo requiere el interés nacional y con cargo de dar cuenta al Congreso. El Congreso puede modificar o derogar los referidos decretos de urgencia". 
Cuadro 5: Decretos legislativos, 1980-2008

\begin{tabular}{|c|c|c|c|c|c|c|c|c|}
\hline Instrumento legal & $\begin{array}{c}\text { F. Belaúnde, } \\
\text { 1980-1985 }\end{array}$ & $\begin{array}{l}\text { A. García, } \\
1985-1990\end{array}$ & $\begin{array}{c}\text { A. Fujimori, } \\
1990-1992\end{array}$ & $\begin{array}{c}\text { A. Fujimori, } \\
1992-1995\end{array}$ & $\begin{array}{c}\text { A. Fujimori, } \\
1995-2000\end{array}$ & $\begin{array}{c}\text { V. Paniagua, } \\
\text { 2000-2001 }\end{array}$ & $\begin{array}{l}\text { A. Toledo, } \\
\text { 2001-2006 }\end{array}$ & $\begin{array}{l}\text { A. García, } \\
2006-2008\end{array}$ \\
\hline Decretos legislativos & $20 \%$ & $13 \%$ & $20 \%$ & $15 \%$ & $9 \%$ & $4 \%$ & $3 \%$ & $18 \%$ \\
\hline Decretos de urgencia & $38 \%$ & $53 \%$ & $72 \%$ & $62 \%$ & $38 \%$ & $49 \%$ & $13 \%$ & $18 \%$ \\
\hline Leyes & $42 \%$ & $34 \%$ & $9 \%$ & $23 \%$ & $54 \%$ & $47 \%$ & $84 \%$ & $64 \%$ \\
\hline Total & $100 \%$ & $100 \%$ & $100 \%$ & $100 \%$ & $101 \%$ & $100 \%$ & $100 \%$ & $100 \%$ \\
\hline
\end{tabular}

Fuente: Sanborn y Morón, 2006.

debatida públicamente. En el Gráfico 4 podemos ver el creciente nivel de fragmentación del sistema, expresado en el número efectivo de partidos con representación en el Congreso. Nótese que entre 2001 y 2003 el número aumenta, así como entre 2006 y 2008, a pesar de estar dentro de un mismo periodo congresal. Esto se explica porque las bancadas electas se fragmentan y dividen a lo largo del periodo. En el Cuadro 6 puede verse la alta volatilidad en el número de escaños de los partidos representados en el Congreso.

La extrema fragmentación del sistema de partidos es favorecida por el sistema electoral. El registro de organizaciones políticas es relativamente laxo, y los congresistas son elegidos mediante un sistema de doble voto preferencial que alienta la competencia intrapartidaria y debilita la cohesión interna. ${ }^{10}$

Gráfico 4: Fragmentación del sistema de partidos según el número efectivo de partidos políticos en el Congreso (NEP), 1980-2006

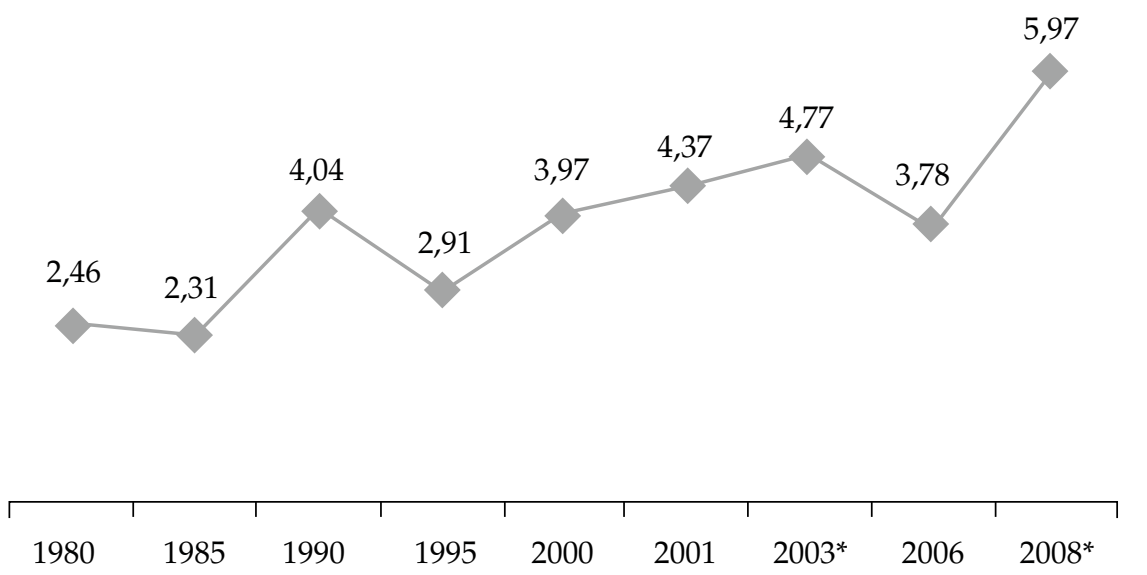

Fuente: Elaborado por los autores.

10 Un conjunto valioso de recomendaciones de cambios en el sistema electoral puede verse en Medina et al., 2007. Sobre el funcionamiento del Congreso en general ver los boletines de Reflexión Democrática, http:// www.reflexiondemocratica.org.pe 
Cuadro 6: Cambios en el Legislativo y volatilidad: 2001, 2006, 2007, 2008

\begin{tabular}{|c|c|c|c|c|}
\hline Partidos/escaños & 2001 & 2006 & 2007 & 2008 \\
\hline Unión por el Perú & 6 & 45 & 9 & 8 \\
\hline Partido Aprista & 28 & 36 & 36 & 36 \\
\hline Partido Nacionalista & 0 & 0 & 22 & 23 \\
\hline Unidad Nacional & 17 & 17 & 15 & 13 \\
\hline Perú Posible & 45 & 0 & 0 & 0 \\
\hline Frente Independiente Moralizador & 11 & 0 & 0 & 0 \\
\hline Somos Perú & 4 & 0 & 0 & 0 \\
\hline Renacimiento Andino & 1 & 0 & 0 & 0 \\
\hline Acción Popular & 3 & 0 & 0 & 0 \\
\hline Todos por la Victoria & 1 & 0 & 0 & 0 \\
\hline Solución Popular & 1 & 0 & 0 & 0 \\
\hline C90 NM & 3 & 0 & 0 & 0 \\
\hline Alianza por el Futuro & 0 & 13 & 13 & 13 \\
\hline Alianza Parlamentaria & 0 & 9 & 9 & 7 \\
\hline Unión por el Perú 2 & 0 & 0 & 11 & 0 \\
\hline Unidad Popular Patriótica & 0 & 0 & 0 & 8 \\
\hline Alianza Nacional & 0 & 0 & 0 & 6 \\
\hline Sin grupo & 0 & 0 & 5 & 6 \\
\hline Total & 120 & 120 & 120 & 120 \\
\hline Volatilidad & - & $58 \%$ & $32 \%$ & $36 \%$ \\
\hline
\end{tabular}

Fuente: Elaborado por los autores.

\section{b. Independencia del Poder Judicial}

A raíz del golpe de Estado de 1992, el fujimorismo intervino el Poder Judicial y emprendió una serie de reformas que terminaron con su funcionamiento autónomo. Una de las primeras medidas fue el nombramiento de nuevos magistrados en calidad de "provisionales", los cuales eran más vulnerables a las presiones políticas. De esta manera se pretendía montar una red de magistrados que favoreciera la impunidad en los actos de corrupción, violación a los derechos humanos y la viabilidad de la segunda reelección de Alberto Fujimori. Luego, en 1995, se creó la Comisión Ejecutiva para el Poder Judicial, conformada por dos miembros nombrados por el Poder Ejecutivo. Esta Comisión supuso la disminución de las atribuciones ordinarias del Poder Judicial, facilitando la implementación del proyecto de reelección presidencial y el acoso a los opositores al régimen. Además se le entregaron poderes para normar la carrera judicial. Es importante recordar que el control del Poder Judicial era un paso clave para intervenir 
a su vez en otras instituciones donde tiene representación, como el Jurado Nacional de Elecciones (JNE) o el Consejo Nacional de la Magistratura.

Caído el fujimorismo, con el proceso de reinstitucionalización democrática, el gobierno de Valentín Paniagua inició una serie de reformas a favor de la recuperación del Estado de derecho en el país. Se planteó una reforma integral del sistema de justicia; sin embargo, gran parte de las recomendaciones de la Comisión Especial para la Reforma Integral de la Administración de la Justicia (CERIAJUS), creada durante el gobierno de Toledo, no han sido implementadas. El control del Poder Judicial por parte del gobierno ha sido en lo fundamental revertido, pero éste sigue siendo una de las instituciones peor evaluadas por la ciudadanía. Al igual que en el caso de la independencia del Legislativo, las deficiencias en el funcionamiento del Poder Judicial tienen que ver con la debilidad institucional del sistema en su conjunto.

Persisten serios problemas de acceso a la justicia en el país, ya sea por sus altos costos, por la lejanía de las oficinas o lo engorroso de los trámites. Dado que más de la mitad de los peruanos vive en situación de pobreza, los costos de tomar alguna acción legal para solucionar conflictos o hacer valer un derecho son muy altos y dificultan el acceso a la justicia entre las poblaciones que más lo necesitan. Una de las medidas propuestas por la CERIAJUS es la exoneración de tasas judiciales en distritos de extrema pobreza en el país. Otra de las limitaciones al acceso a la justicia tiene está en la diversidad cultural y lingüística que el Estado no ha sabido recoger en su funcionamiento diario. Aunque todas las personas tienen derecho a ser atendidas en su lengua materna, los funcionarios de justicia suelen desconocer el idioma nativo de la localidad y no cuentan con intérpretes para atender a las personas que hablan alguna de las cientos de lenguas existentes en el territorio nacional.

El nuevo código procesal penal ha sido uno de los mayores avances en la reforma de la justicia en el Perú, pues busca hacer más cercanos, rápidos y eficientes los procesos judiciales. Promulgado mediante el decreto legislativo 957 de julio del 2004, el nuevo código presenta como una de sus principales medidas la inversión pública en la creación de nuevos despachos y la contratación de nuevo personal, la incorporación de la oralidad en los juicios para hacerlos más rápidos y transparentes y una mejor separación de funciones entre la policía, el ministerio público y el Poder Judicial. Con el mismo espíritu existen propuestas para garantizar el acceso a la justicia de las poblaciones en situación de pobreza, eliminar la corrupción en el Poder Judicial, aligerar y modernizar el funcionamiento de las oficinas judiciales y aumentar la calidad profesional de los magistrados. Sin embargo, la reforma general del sistema de justicia en el Perú avanza a pasos muy lentos; por ello, la confianza en el Poder Judicial se ha mantenido muy baja. ${ }^{11}$ 


\section{c. Relaciones entre civiles y militares}

En el caso de las instituciones militares observamos esfuerzos importantes para reformar su funcionamiento y mejorar las relaciones con los civiles y los poderes constitucionales. Las instituciones militares requieren de modernización, reorganización, profesionalización, eliminación de la corrupción y una estricta subordinación a la autoridad política.

En la década de los años noventa las Fuerzas Armadas fueron controladas por el asesor de inteligencia Vladimiro Montesinos, se politizaron y se vieron envueltas en graves casos de corrupción y violación a los derechos humanos, que se sumaron a los múltiples casos provenientes de la década anterior, marcada por el conflicto armado interno, y la aplicación de una estrategia contrasubversiva que, según la Comisión de la Verdad y Reconciliación, "implicó, en algunos lugares y momentos, la violación sistemática de los derechos humanos".

Desde 2001 ha habido un proceso de depuración y reforma en la relación entre civiles y militares. Se han dado avances importantes en la eliminación de la influencia de las redes mafiosas formadas bajo la influencia de Montesinos y en el fortalecimiento de la conducción civil en temas de defensa. Sin embargo, se ha visto poco progreso en cuanto a lograr que las fuerzas armadas asuman la necesidad de investigar y sancionar los casos de violación a los derechos humanos.

A pesar de estas tensiones, las fuerzas armadas son una de las cinco instituciones con la confianza ciudadana más alta. Según IPSOS-Apoyo en septiembre del 2008 las fuerzas armadas alcanzaban un $49 \%$ de confianza, colocándose muy por encima del promedio de todas las instituciones públicas. Esto se explica porque, a pesar de las tensiones sobre el tema de los derechos humanos y de la complicidad con el autoritarismo y corrupción durante el gobierno de Fujimori, la ciudadanía reconoce que las fuerzas armadas jugaron un papel fundamental en la derrota del terrorismo.

En la relación entre civiles y militares cabe distinguir dos etapas tras el periodo iniciado en 2001. En una primera etapa, el poder civil aprovechó el desgaste y desprestigio de las Fuerzas Armadas para llevar a cabo reformas, lo que se expresó también en una caída en la participación de las fuerzas armadas en el presupuesto público. Sin embargo, después de 2004 los militares lograron neutralizar los intentos de reforma, y recuperaron su participación presupuestal. Una muestra de esto fue la creación del Fondo para las Fuerzas Armadas y la Policía en 2004, establecido como un porcentaje de las regalías del proyecto de explotación de gas de Camisea. ${ }^{12}$

12 Sobre estos asuntos ver las publicaciones del área de defensa y reforma militar del Instituto de Defensa Legal, en: http:/ /www.defensaidl.org.pe 


\section{DEMOCRACIA DE CIUDADANOS}

\section{a. Derechos civiles}

En cuanto a las libertades de expresión y reunión, los problemas aparecen asociados a respuestas represivas que tienen los gobiernos frente a situaciones de protesta y movilización social. Muchas veces estos movimientos han seguido formas no-institucionales y violentas de acción colectiva, en ocasiones cuestionando proyectos de inversión de interés para el gobierno. Frente al escenario de estas movilizaciones, el gobierno ha tenido la tentación de caer en salidas represivas. La retórica hostil y agresiva hacia los sectores que protestan se ha acentuado durante los dos primeros años del gobierno aprista.

En este gobierno ha habido episodios muy tensos en la relación entre el gobierno y las organizaciones no gubernamentales vinculadas a la defensa de los derechos humanos. Dos iniciativas legislativas se pusieron en discusión para limitar las libertades de estas organizaciones; la primera fue la ley que modificaba las atribuciones de la Agencia Peruana de Cooperación Internacional (APCI) ${ }^{13}$ y determinaba que las organizaciones privadas que recibieran fondos de cooperación internacional podían ser controladas y pasibles de sanciones mediante procedimientos administrativos por parte de la APCI. Esta propuesta fue cuestionada, pues vulneraba las libertades de las organizaciones privadas. La polémica fue llevada al Tribunal Constitucional que se pronunció a favor de la inconstitucionalidad de tres artículos de dicha ley, ${ }^{14}$ aclarando que sólo estarían bajo el régimen de la APCI aquellas instituciones cuyos fondos de cooperación internacional fueran gestionados por el Estado. La segunda ley que generó polémica fue un proyecto presentado por el Ejecutivo que proponía modificaciones a la Ley General de Sociedades y al Código Civil para poder disolver asociaciones que atentasen contra el orden público. Esta iniciativa tampoco llegó a concretarse. Estas acciones muestran un gobierno hostil ante instituciones civiles críticas o vinculadas a otros proyectos políticos, pero que, en última instancia, retrocede ante las críticas. El presidente Alan García ha defendido tales puntos de vista a través de los artículos intitulados "El Perro del Hortelano", donde presenta como enemigos del desarrollo del país a quienes se oponen o son críticos de, por ejemplo, grandes proyectos de inversión minera.

Por otro lado, la cantidad de regiones en estado de emergencia, donde algunos derechos constitucionales son restringidos, es significativa. Los enfrentamientos y emboscadas en las zonas cocaleras, donde actúan narcotraficantes y remanentes de Sendero Luminoso, han provocado que el gobierno declare en estado de emergencia a regiones como Ayacucho, Cusco, Huancavelica y Junín. Por estas razones y otras de orden social como el terremoto de agosto de 2007 o el excesivo frío en las zonas andinas, se han declarado con cierta regularidad estados de emergencia en varias localidades del país. ${ }^{15}$

Ley 28925, publicada el 8 de diciembre del 2006.

Resolución 0009-2007-PI/TC del Tribunal Constitucional.

Sobre la situación de los derechos civiles y políticos en el Perú ver los reportes anuales de la Coordinadora Nacional de Derechos Humanos sobre la situación de los derechos humanos. 


\section{b. Derechos políticos}

A diferencia de lo ocurrido durante el gobierno de Fujimori, los derechos políticos son respetados y protegidos. No hay restricciones significativas a la pluralidad política, pero existen serios problemas de calidad de la oferta y del debate público que involucran a sus principales protagonistas, los partidos y los medios de comunicación.

En los medios de comunicación no hay una tradición de un periodismo que se presenta como imparcial y objetivo; por el contrario, se tiende a defender banderas ideológicas y a tener alineamientos partidarios. Si bien existe una amplia variedad de medios, el resultado agregado es que la información y el debate público aparecen muy sesgados, lo que crea un problema de desconfianza en la ciudadanía. El peso del dinero e intereses de los más poderosos tiende a imponerse, sobre todo durante las campañas electorales, por lo que es necesario legislar de manera efectiva sobre la financiación de los gastos de campaña.

Por otro lado, las agrupaciones políticas tienen bajos niveles de institucionalización y carecen de orientaciones programáticas claras, así como de personal preparado para asumir cargos públicos. La debilidad de los partidos repercute en la debilidad institucional del Estado para elaborar políticas públicas que favorezcan a las mayorías, manteniendo alejados y neutralizados los intereses privados.

Los principales problemas que atentan contra las libertades políticas de los ciudadanos es la debilidad de las instituciones, la calidad de la representación y del debate público. Los partidos en el Perú despiertan los menores niveles de confianza de la región, según datos del Latinobarómetro 2008, mientras que los diarios exhiben una confianza promedio en el contexto regional.

\section{c. Derechos económicos y sociales}

Uno de los principales problemas de la democracia peruana es que los últimos gobiernos no han logrado mejorar de manera importante las condiciones sociales y disminuir los niveles de pobreza, a pesar del periodo de importante crecimiento económico de los últimos años, muy superior al promedio de la región (Gráfico 5). Según datos del INEI, entre 2004 y 2005 la tasa de pobreza se mantuvo constante (48,6 y 48,7\% de la población total, respectivamente); bajó ligeramente en 2006 al 44,5\% y un poco más en 2007, al $39,3 \%$. La pobreza extrema pasó del $17,1 \%$ en 2004 a un 13,7\% en 2007. Sin embargo, se teme que la crisis internacional iniciada a finales de 2008 no permita avanzar en los próximos años. Otros países de la región con desempeños económicos más modestos han logrado avances más importantes en el combate a la pobreza.

El nivel de gasto social se ha mantenido muy por debajo del promedio regional y ha mostrado una tendencia irregular de crecimiento. Entre el 2001 y el 2006 el porcentaje del PIB destinado al sector salud pasó de 1,2\% a 1,1\%. En el caso del sector educación, lo gastado entre el 2001 y el 2005 bajó de 3 a 2,6\% del PIB. Además, en comparación con el promedio latinoamericano, las proporciones del PIB que Perú asigna a esos sectores son bajas (Gráficos 6 y 7). En 2005, por ejemplo, el porcentaje del gasto en educación 
Gráfico 5: Tasas de variación del PBI, 1990-2007

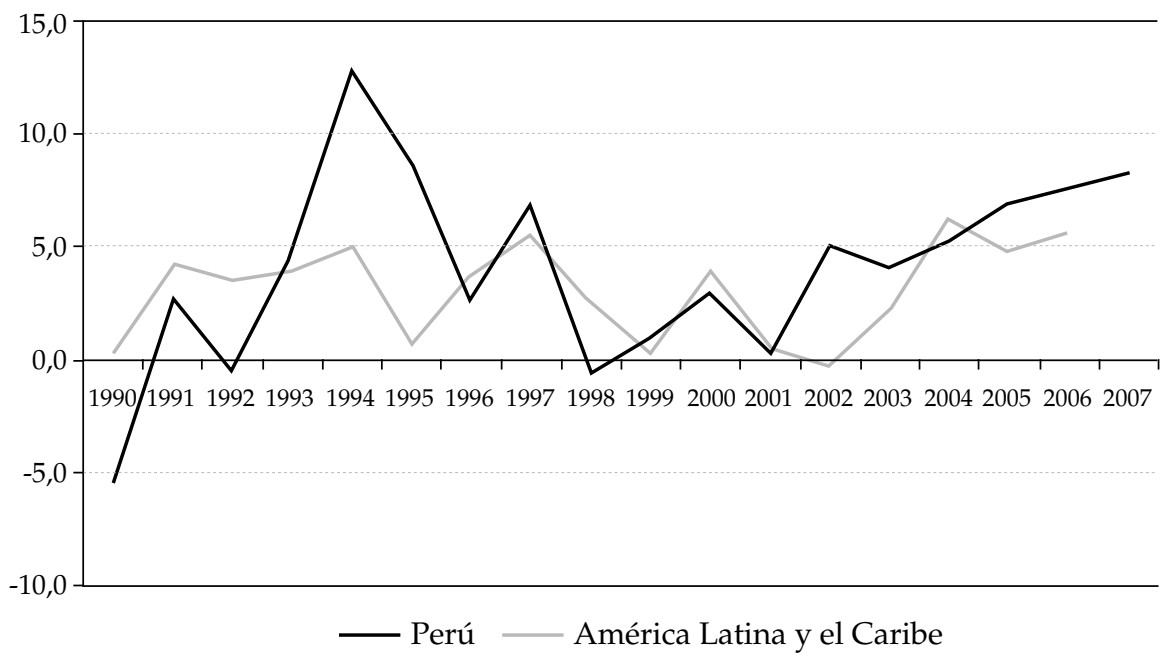

Fuente: CEPAL, 2007.

en Perú fue el tercero más bajo de toda América Latina y el Caribe. En cuanto al sector salud, en 2006 Perú aparece en el último lugar de toda la región.

Gráfico 6: Porcentaje del PIB destinado a Gráfico 7: Porcentaje del PIB destinado a salud educación
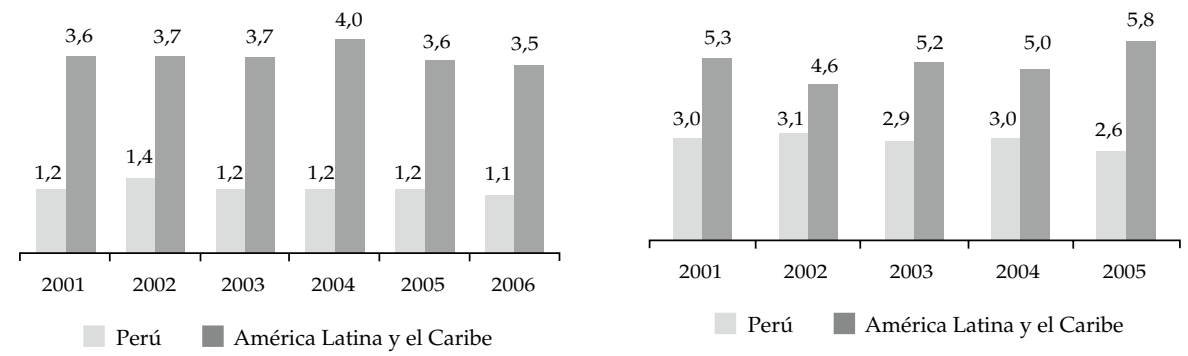

Fuente: CEPAL, 2007.

\section{LA SITUACIÓN RECIENTE}

Para terminar, presentamos algunas ideas sobre la situación más reciente y los desafíos que se presentan para la democracia en el Perú. ${ }^{16}$

16 Sobre estos asuntos ver también, desde perspectivas diferentes, Dargent, 2009; Lynch, 2009; Adrianzén, 2009, entre otros. 
Los límites de los intentos de institucionalización democrática se expresaron en las elecciones de 2006, que enfrentaron a un candidato con un discurso crítico contra el sistema (Ollanta Humala) contra un candidato que era parte de los actores tradicionales del sistema y promovía el cambio social, pero de manera "responsable" (Alan García). En esas elecciones se manifestaron antagonismos regionales, étnicos y de clase con una fuerza nunca antes vista en el país desde el inicio de la experiencia democrática en 1980. Tanaka y Vera (2009) han analizado la correlación entre la votación por candidatos presidenciales "contestatarios" a nivel provincial y algunos indicadores de ruralidad, identidad étnica y nivel de desarrollo humano, encontrando que las correlaciones más altas en esos tres indicadores se dieron en las elecciones de 2006. El resurgimiento de la centralidad política de estos conflictos es expresión elocuente de los efectos que ha generado el patrón de crecimiento de los últimos años y del limitado efecto que las reformas institucionales han tenido sobre el sistema político. ${ }^{17}$

Cuadro 7: Correlación entre voto, ruralidad, etnicidad e Índice de Desarrollo Humano

\begin{tabular}{|c|c|c|c|}
\hline Porcentaje de votación válida & Ruralidad & Etnicidad & $\mathrm{IDH}$ \\
\hline $\begin{array}{l}\text { Izquierdas, } 1980 \\
\text { (PTR, FPCEP, UDP, IU, UNIR) }\end{array}$ & N.S. & $0.318^{* *}$ & N.S. \\
\hline Izquierda Unida, 1985 (A. Barrantes) & N.S. & $0.504^{* *}$ & N.S. \\
\hline Cambio90, 1990: 1era vuelta (A. Fujimori) & N.S. & $0.226^{* *}$ & $0.224^{* *}$ \\
\hline Cambio90, 1990: 2da vuelta (A. Fujimori) & N.S. & $0.625^{* *}$ & $-0.412^{* *}$ \\
\hline C90NM, 1995 (A. Fujimori) & N.S. & N.S. & N.S. \\
\hline Perú 2000, 2000: 1era vuelta (A. Fujimori) & N.S. & $-0.365^{* *}$ & N.S. \\
\hline Perú 2000, 2000: 2da vuelta (A. Fujimori) & N.S. & $-0.514^{* *}$ & $0.199^{* *}$ \\
\hline Perú Posible, 2000: 1era vuelta (A. Toledo) & N.S. & $0.282^{* *}$ & N.S. \\
\hline Perú Posible, 2000: 2da vuelta (A. Toledo) & N.S. & $0.508^{* *}$ & $-0.196^{* *}$ \\
\hline Perú Posible, 2001: 1era vuelta (A. Toledo) & N.S. & $0.608^{* *}$ & $-0.409^{* *}$ \\
\hline Perú Posible, 2001: 2da vuelta (A. Toledo) & $0.413^{*}$ & $0.713^{* *}$ & $-0.493^{* *}$ \\
\hline UPP-PNP, 2006: 1era vuelta (O. Humala) & N.S. & $0.754^{* *}$ & $-0.489^{* *}$ \\
\hline UPP-PNP, 2006: 2da vuelta (O. Humala) & $0.526^{* *}$ & $0.729^{* *}$ & $-0.587^{* *}$ \\
\hline
\end{tabular}

**N.S.: No significativo al $95 \%$.

Fuente: Tanaka y Vera, 2009. 
En términos regionales, entre 2004 y 2006 la pobreza en los ámbitos rurales se mantuvo constante a pesar de que se reducía en los ámbitos urbanos y la economía crecía de manera sostenida; mientras que la pobreza en general afectó al 37,1\% de la población urbana en 2004, al 36,8 en 2005 y al 31,2 en 2006, ella afectó al 69,8\% de la población rural en 2004, al 70,9 en 2005 y al 69,3 en 2006. En los departamentos de Apurímac, Ayacucho, Huancavelica, Junín, Pasco y San Martín, la pobreza aumentó entre 2004 y 2006. De otro lado, según cifras de 2006 y 2007, la pobreza afecta particularmente a la población indígena: en 2006 el porcentaje de pobres llegó al 66\% entre quienes hablan lenguas nativas, y afectó al 38,2\% de quienes hablan castellano; en 2007, los porcentajes son 63,1 y 32,6 , respectivamente. No es casualidad entonces que el descontento ciudadano frente al sistema político haya sido especialmente fuerte en ámbitos rurales, en el sur andino y en la sierra sur.

Estos resultados generaron una conciencia nacional sobre la importancia de que el segundo gobierno de Alan García tuviera como prioridad el combate a la pobreza y la exclusión social. Sin embargo, después de más de dos años de gestión, los clivajes expresados en las elecciones de 2006 parecen vigentes. La aprobación a la gestión del Presidente García cayó de manera constante desde el inicio de su gobierno, pasando de $58 \%$ en agosto de 2006 a 19\% en noviembre de 2008 (Gráfico 8). Es de especial importancia registrar las diferencias clasistas y regionales en la aprobación a su gestión (Cuadros 8 y 9): en septiembre de 2008, mientras que en los sectores socioeconómicos A y B un 40\% de los encuestados aprobaba la gestión de García, en los sectores D y E apenas un 10\% lo hacía. En cuanto a las diferencias regionales, mientras que en Lima $24 \%$ de los entrevistados aprobaba la gestión, en el sur y el oriente 11\% y 14\% lo hacía.

Gráfico 8: Aprobación presidencial. Agosto 2006-septiembre 2008

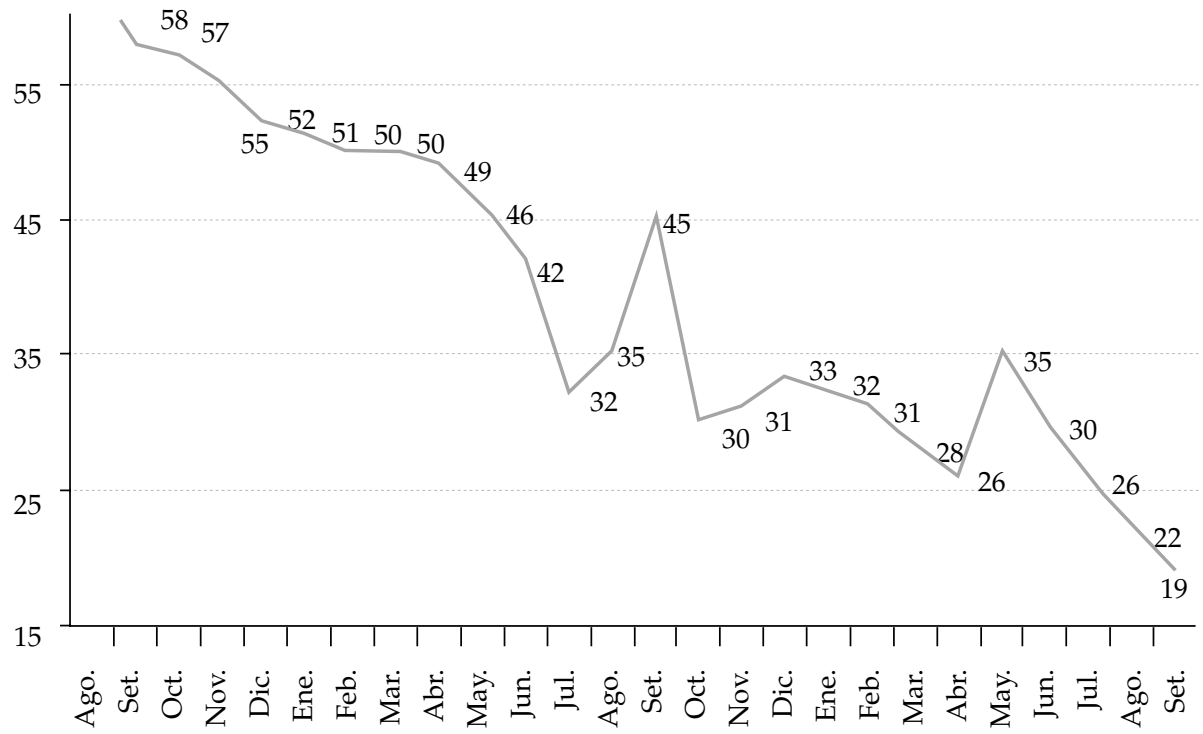


Cuadro 8: Aprobación presidencial según nivel socioeconómico.

Enero-septiembre 2008.

\begin{tabular}{cccc}
\hline NSE & A/B & C & D/E \\
\hline Ene. & 44 & 35 & 26 \\
Feb. & 49 & 30 & 26 \\
Mar. & 38 & 31 & 22 \\
Abr. & 36 & 24 & 23 \\
May. & 59 & 32 & 33 \\
Jun. & 48 & 31 & 22 \\
Jul. & 48 & 24 & 18 \\
Ago. & 34 & 24 & 15 \\
Sep. & 40 & 21 & 10 \\
\hline
\end{tabular}

Fuente: Ipsos-Apoyo.

Cuadro 9: Aprobación presidencial según región. Enero-septiembre 2008.

\begin{tabular}{ccccc}
\hline Región & Norte & Centro & Sur & Oriente \\
\hline Ene. & 25 & 29 & 26 & 17 \\
Feb. & 29 & 30 & 16 & 22 \\
Mar. & 29 & 16 & 16 & 15 \\
Abr. & 24 & 20 & 14 & 11 \\
May. & 40 & 28 & 16 & 13 \\
Jun. & 26 & 30 & 7 & 11 \\
Jul. & 32 & 18 & 11 & 10 \\
Ago. & 16 & 12 & 4 & 17 \\
Sep. & 19 & 9 & 11 & 14 \\
\hline
\end{tabular}

Fuente: Ipsos-Apoyo.

Otra manifestación del descontento social son los abundantes conflictos que se desarrollan cada vez con más frecuencia en todo el territorio nacional. Según los reportes de la Defensoría del Pueblo, los conflictos minero-ambientales y aquellos que cuestionan a autoridades locales son los más frecuentes. Estos conflictos tienen un potencial disruptivo muy alto, en tanto afectan grandes proyectos relacionados con las exportaciones del país. Estas protestas muestran una gran fragmentación y localismo (Gráfico 9), por lo 
que, si bien ponen en aprietos al gobierno en coyunturas específicas, no se acumulan ni convergen bajo liderazgos o banderas más grandes.

Gráfico 9. Ámbito de las protestas por año (1995-2006)

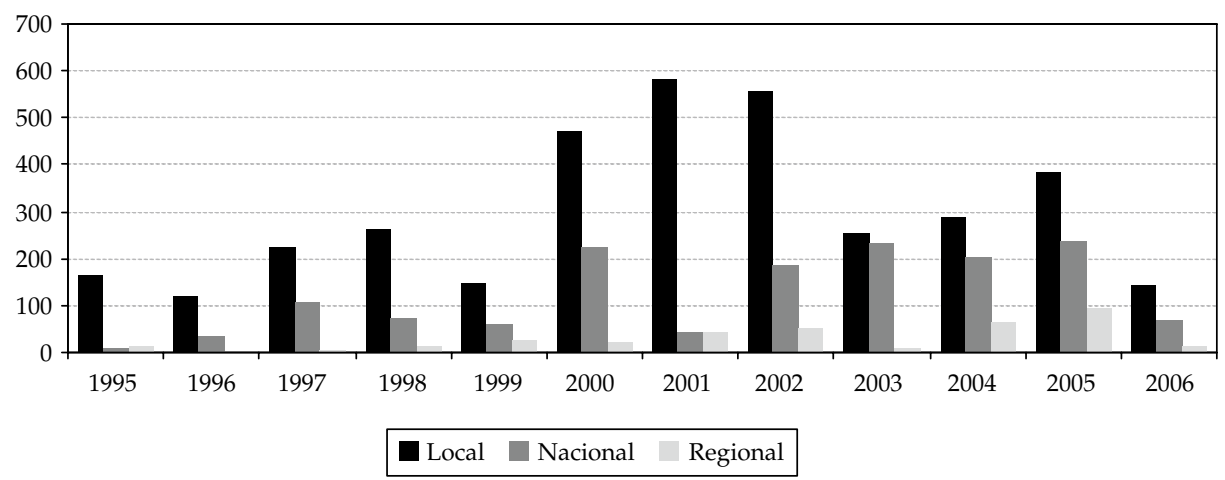

Fuente: Tanaka y Garay, 2009.

El gobierno actual parece confiar que tarde o temprano el crecimiento económico se dejará sentir en el país, y éste legitimará su gestión y a las instituciones democráticas en general. El nivel de pobreza, que se mantuvo constante entre 2004 y 2006, bajó de manera importante en 2007; asimismo, el porcentaje de ciudadanos que aprueba la gestión del presidente, que cayó sistemáticamente entre agosto de 2006 y finales de 2008, se ha ido recuperando lentamente a lo largo de 2009, hasta llegar al 29\% en diciembre de 2009. Sin embargo, este optimismo se vuelve relativo frente a la incertidumbre de la situación actual, marcada por una nueva crisis internacional que se expresa en la caída en los precios de los productos de exportación. El país tendrá elecciones regionales y locales a finales de 2010 y elecciones generales en 2011 y el panorama se perfila similar a las elecciones de 2006, es decir, antagonismos de clase, regionales y étnicos, con una dinámica "neodualista", en la que una parte del país avanza mientras que otra se queda rezagada.

La pregunta que habría que hacerse es por qué en los últimos años el Estado peruano no ha logrado tener resultados importantes en sus políticas sociales, que puedan cambiar el panorama político. En otros países, en plazos relativamente cortos, políticas sociales agresivas son capaces de cambiar la demografía electoral, como en Brasil con el gobierno de Lula (Hunter y Power, 2007). En el Perú mismo, el referéndum de 1993 mostraba que el apoyo a Fujimori era mayor en Lima y las principales ciudades, y menor en las provincias; después de 1995, con la implementación de programas como FONCODES y otros, el fujimorismo se hizo fuerte en las provincias y en los ámbitos rurales (Arce, 1996). ¿Por qué con la "reinstitucionalización democrática" no se ha logrado algo equivalente? Consideramos que la explicación hay que buscarla en el debilitamiento de la institucionalidad estatal, así como en el debilitamiento de las capacidades de gestión de los actores políticos ocurrido durante el fujimorismo. Durante este gobierno hubo 
una reconstitución autoritaria del Estado (Burt, 2009) después del colapso de finales de la década de los años ochenta; esto hizo que el Estado recuperara presencia en áreas clave de la política macroeconómica y en los aparatos de control interno, pero el conjunto del aparato público sufrió de la imposición de un estilo de gobierno signado por prácticas centralistas, autoritarias y clientelísticas. Caído el fujimorismo, tenemos en el Estado elencos políticos sin cuadros con suficiente experiencia, que enfrentan un aparato público que logró niveles importantes de eficiencia en algunas "islas" del Estado, quedando las áreas sociales muy debilitadas. Además, en un contexto democrático, que impulsa políticas de descentralización, no existe el expediente de salidas centralistas, autoritarias o clientelísticas, con lo que se generan serios problemas de eficiencia. Esto permite entender que en el país la política macroeconómica haya tenido una continuidad que ha favorecido el crecimiento económico, pero también la reproducción de brechas y diferencias sociales; y que al mismo tiempo el Estado no haya logrado en los últimos años implementar políticas sociales capaces de aminorarlas de manera significativa.

Si los límites de la democracia peruana se encuentran en la debilidad de las instituciones y en la debilidad de los actores políticos y sociales, la agenda prioritaria pasa por fortalecerlos. Para fortalecer a los partidos se debe limitar el oportunismo, el personalismo y la improvisación, por lo que las barreras de entrada al sistema político se deben hacer más exigentes. Debe haber esfuerzos deliberados por fortalecer la capacidad organizativa y propositiva de los actores sociales y no confiar que abriendo espacios participativos la calidad democrática mejorará de manera automática. El fortalecimiento del Estado, de los partidos y de las organizaciones de la sociedad civil facilitará que la democracia peruana sea más sensible a las demandas de integración social, lo que permitirá mejorar la calidad democrática.

\section{REFERENCIAS}

Adrianzén, Alberto. 2009. La transición inconclusa. De la década autoritaria al nacimiento del pueblo. Lima, ed. Otra mirada.

Ames, Rolando y Diego Ponce de León. 2009. “La elección presidencial peruana del 2006: descontentos y satanizadores". En: Orlando Plaza, coord., Cambios sociales en el Perú: 1968-2008. Lima, CISEPAPUCP.

Arce, Moisés, 1996. “¿Qué tan eficiente es la política social del FONCODES?” En: Pretextos, No 9, pp. 95-113. Lima, DESCO.

Burt, Jo-Marie, 2009. Violencia y autoritarismo en el Perú: bajo la sombra de Sendero y la dictadura de Fujimori. Lima, IEP-SER.

Cameron, Maxwell, y Philip Mauceri, eds., 1997. The Peruvian Laberynth: Polity, Society, Economy. Pennsylvania State University Press, pp. 37-69.

Carrión, Julio ed., 2006. The Fujimory Legacy. The Rise of Electoral Authoritarianism in Peru. Pennsylvania, Penn State UP.

Comisión Económica para América Latina (CEPAL). 2007. Anuario Estadístico de América Latina y el Caribe. CEPAL.

Comisión Especial para la Reforma Integral de la Administración de la Justicia (CERIAJUS). 2004. “Plan de reforma de la Administración de Justicia de la CERIAJUS: el acuerdo por la justicia que debemos respetar". Lima: Consorcio Justicia Viva. Disponible en: http://www.justiciaviva.org.pe/publica/ reformaceriajus.pdf 
Coordinadora Nacional de Derechos Humanos (CNDDHH). 2007. Informe anual acerca de la situación de los derechos humanos 2007. Lima: CNDDHH.

Crabtree, John, ed. 2006. Construir instituciones: democracia, desarrollo y desigualdad en el Perú desde 1980. Lima, Lima, Red para el Desarrollo de las Ciencias Sociales.

Dargent, Eduardo, 2009. Demócratas precarios. Élites y debilidad democrática en el Perú y América Latina. Lima, IEP.

2006. "La reforma judicial en el Perú, 1990-2005". En: John Crabtree ed., Construir instituciones: Democracia, desarrollo y desigualdad en el Perú desde 1980. Lima, Red para el Desarrollo de las Ciencias Sociales.

Grompone, Romeo y Martín Tanaka, eds., 2009. Las protestas sociales en el Perú actual. Entre el crecimiento económico y la insatisfacción social. Lima, Instituto de Estudios Peruanos.

Hunter, Wendy, y Timothy Power, 2007. "Rewarding Lula: Executive Power, Social Policy, and the Brazilian Elections of 2006". En: Latin American Politics and Society, vol. 49, No 1, Spring, pp. 1-30.

Jones, Mark P. 2005. "The role of parties and party systems in the policymaking process" En State reform, public policies, and policymaking processes. Washington: BID.

Latin American Public Opinion Project (LAPOP). 2006. Auditoría de la Democracia en Chile 2006. Santiago: Vanderbilt University e Instituto de Ciencia Política, PUC.

Lynch, Nicolás, 2009. El argumento democrático sobre América Latina. La excepcionalidad peruana en perspectiva comparada. Lima, UNMSM.

Medina, Percy et al. 2007. La otra reforma: 40 soluciones elementales para la legislación electoral. Lima: Transparencia-IDEA.

Payne, Mark, et al. 2003. La política importa. Democracia y desarrollo en América Latina. Washington D.C., BID-IDEA.

Programa de las Naciones Unidas para el Desarrollo (PNUD). 2004. La democracia en América Latina. Hacia una democracia de ciudadanas y ciudadanos. Nueva York: PNUD.

Remy, María Isabel. 2005. Los múltiples campos de la participación ciudadana en el Perú. Un reconocimiento del terreno y algunas reflexiones. Lima, Instituto de Estudios Peruanos.

2008. "Y se vienen las revocatorias". En: Argumentos, año 2, No 1, mayo. Lima, Instituto de Estudios Peruanos.

Sanborn, Cynthia y Eduardo Morón. 2006. "The pitfalls of policymaking in Peru: actors, institutions and rules of the game". Documento de trabajo R-511, Washington: BID.

Sulmont, David, 2009. "Líneas de frontera y comportamiento electoral en el Perú. Diferencias sociales y tendencias del voto en las elecciones presidenciales peruanas: 1980-2006. En: Orlando Plaza, coord., Cambios sociales en el Perú: 1968-2008. Lima, CISEPA-PUCP.

Tanaka, Martín y Carolina Garay, 2009. “Las protestas en el Perú entre 1995 y el 2006”. En: Grompone, Romeo y Martín Tanaka, eds.: Las protestas sociales en el Perú actual. Entre el crecimiento económico y la insatisfacción social. Lima, Instituto de Estudios Peruanos, 2009 (pp. 59-123).

Tanaka, Martín y Sofía Vera. 2007. "Perú: entre los sobresaltos electorales y la agenda pendiente de la exclusión". Revista de Ciencia Política 27 (número especial): pp. 235-248.

2008. "El "neodualismo" de la política peruana". Revista de Ciencia Política 28(1): 347-365.

2009. “Escisiones persistentes y representación política: clivajes étnicos, clasistas y regionales en las actitudes políticas de los peruanos". Inédito.

Tanaka, Martín. 1998. Los espejismos de la democracia. El colapso del sistema de partidos en el Perú, 1980-1995, en perspectiva comparada. Lima, Instituto de Estudios Peruanos.

. 2001. “¿Crónica de una muerte anunciada? Determinismo, voluntarismo, actores y poderes estructurales en el Perú, 1980-2000". En Lecciones del final del fujimorismo. La legitimidad presidencial y la acción política editado por Jane Marcus y Martín Tanaka. Lima: Instituto de Estudios Peruanos.

2006. "From Crisis to Collapse of the Party Systems and Dilemmas of Democratic Representation: Peru and Venezuela". En The Crisis of Democratic Representation in the Andes editado por Scott Mainwaring, Ana María Bejarano y Eduardo Pizarro. Stanford: Stanford University Press.

Tuesta Soldevilla, Fernando. 2001. Perú Político en cifras (1821-2001). Lima: Fundación Friedrich Ebert. Vergara, Alberto, 2007. Ni amnésicos ni irracionales. Las elecciones peruanas de 2006 en perspectiva histórica. Lima, Solar. 
Martín Tanaka. Peruano. Doctor en Ciencia Política y Maestro en Ciencias Sociales por la Facultad Latinoamericana de Ciencias Sociales (FLACSO) sede México; y Licenciado en Sociología por la Pontificia Universidad Católica del Perú. Actualmente es investigador asociado en el Instituto de Estudios Peruanos y profesor del Departamento de Ciencias Sociales de la Pontificia Universidad Católica del Perú. Es columnista semanal en el diario Perú21. Ha sido Director General del Instituto de Estudios Peruanos (2005-2007), Visiting Fellow en el Helen Kellogg Institute for International Studies de la Universidad de Notre Dame, Indiana (2003) y profesor visitante en la Maestría de Ciencia Política de la Universidad de los Andes en Bogotá (2002). Temas de investigación: democracia, política y partidos; movimientos sociales y participación ciudadana; cultura política, en Perú y América Latina. Tiene libros y capítulos de libros publicados en el Perú por el Instituto de Estudios Peruanos y la Comisión Andina de Juristas; fuera del Perú, por Cambridge University Press, Stanford University Press, IDEA Internacional, Fundación Pablo Iglesias, Brookings Institution Press (Washington DC), Homo Sapiens eds. (Rosario, Argentina), Lynne Rienner Publishers (Boulder, Colorado), The University of London, el Instituto de Estudios Sociales de la Universidad Nacional Autónoma de México (IISUNAM), Universidad Iberoamericana, entre otros.

(E-mail: mtanaka@iep.org.pe)

Sofía Vera Rojas es bachiller en sociología de la Pontificia Universidad Católica del Perú. Actualmente es asistente de investigación en el Instituto de Estudios Peruanos y asistente de cátedra en el Departamento de Ciencias Sociales de la Pontificia Universidad Católica del Perú.

(E-mail: svera@iep.org.pe) 